\title{
Editorial
}

\section{The Many Meanings of Evidence: Implications for the Translational Science Agenda in Healthcare}

\section{Gill Harvey ${ }^{\star}$}

Manchester Business School, University of Manchester, Manchester, UK

Received: 1 September 2013, Accepted: 16 September 2013, ePublished: 21 September 2013

\begin{abstract}
Health systems across the world are concerned with the quality and safety of patient care. This includes investing in research and development to progress advances in the treatment and management of individuals and healthcare organisations. The concept of evidencebased healthcare has gained increasing currency over the last two decades; yet questions persist about the time it takes for new research evidence to find its way into day to day healthcare decision-making. This paper explores the reasons for this apparent gap between research and healthcare practice, management and policy-making. In particular, the paper argues that different meanings attached to the word 'evidence' fundamentally influence the way in which the research-practice gap is conceptualised and subsequent strategies that are implemented to increase the uptake of research.

Keywords

Knowledge Translation, Evidence-based Healthcare, Research Utilisation
\end{abstract}

$\mathrm{T}$ The last twenty to thirty years have seen a growth of interest and activity to promote evidence-based practice, management and policy in healthcare. Aware of the difference between what research indicates is best practice and the scale and speed with which that research is routinely used in healthcare decision-making, policy makers at a national and international level have sought to find ways to improve the uptake of evidence. Some studies $(1,2)$ have suggested that $30-40 \%$ of patients do not receive care complying with current scientific evidence. Others have highlighted the limited role that research evidence plays in managerial and policy decisions (3), to the extent that decisions sometimes appear to fly in the face of available evidence (4).

Various strategies have been adopted to promote more evidence-based decision-making in healthcare, including the establishment of methods, networks and organisations to appraise and synthesise existing research. This has resulted in the development of rigorous methods of systematic review, the setting up of review groups, such as the international Cochrane Collaboration, the Joanne Briggs Institute, and the creation of national organisations such as the National Institute for Health and Care Excellence (NICE) in the English National Health Service (NHS) to undertake technology appraisals and produce national clinical guidelines. Yet despite the wealth of activity to make evidence more available and more accessible to people working within healthcare, whether they are clinicians, managers, commissioners or policy makers, the implementation of evidence into routine decision-making at a clinical, organisational and policy level remains slow, challenging and difficult. Why then is this the case? Given the growth of information technology and the relative ease with which information can now be made available and accessed by those seeking knowledge, why do the apparent gaps between evidence and practice persist?

In seeking answers to this question, one fundamental point to consider is the different meanings that are attached to knowledge and evidence, in particular the juxtaposition that exists between the biomedical and social science traditions in healthcare. Whilst it is generally recognised that knowledge encompasses both explicit and tacit dimensions $(5,6)$, the extent to which these are recognised and acknowledged can vary considerably across different disciplines. For example, in medical science, knowledge is typically viewed from the more formal, explicit perspective (7) and objective research findings, in a form that 'evidence' occupies a more privileged status than the more tacit, practical, 'know-how' form of knowledge. Thus we see hierarchies of evidence used to grade the 'quality' of evidence, depending on its source and the related level of robustness and rigour. Typically such hierarchies rate research evidenceand particular types of research evidence-much higher than expert opinion or professional consensus. By contrast, social scientists typically see knowledge as being socially situated, inclusive of both explicit and tacit dimensions and subject to influence by wider social structures and norms, including power relationships (8).

Differences and distinctions such as these have important implications. Firstly, in relation to commonly applied hierarchies of evidence, it is important to note that they are particularly focused on questions of effectiveness (does intervention A lead to outcome B?). However, in planning and delivering services, effectiveness may not be the only consideration: for example, a particular intervention may have research evidence to demonstrate its effectiveness, but may be unacceptable to particular patient groups or be too expensive to be made accessible to everybody who could potentially

^Corresponding author: Gill Harvey; Email: gill.harvey@mbs.ac.uk 
benefit from it. Secondly, and of particular importance from an implementation perspective, the dominant conceptualisation of evidence influences the ways in which the gaps between evidence and practice are perceived and the strategies that are proposed to bridge the evidence-practice gap. Where formal, explicit knowledge is privileged, the 'gap' is typically perceived as a knowledge transfer problem, whereby objective, scientific knowledge that has been produced by the research community needs to be transferred to the practice community. This has resulted in the use of terminology such as 'knowledge transfer', 'knowledge translation' and 'knowledge utilisation', where the emphasis is on starting with knowledge from research evidence and finding ways to make that evidence more accessible, useful and usable by practitioners at a clinical, managerial and policymaking level. Hence the emphasis is on developing methods to synthesise research evidence and to make it available in more accessible forms, to understand the barriers to research use amongst targeted communities and to develop and test implementation interventions directed at closing the researchpractice gap.

Critics, however, would argue that such initiatives, premised on a research-gap and seeking to find a knowledge transfer solution, are constrained by the overly narrow definition of knowledge and a misunderstanding of how and why the knowledge-practice gap exists $(7,9,10)$. Greenhalgh and Wieringa (7) suggest that there are three widely held assumptions underpinning conventional knowledge translation strategies which limit their usefulness in practice: firstly, an objective view of knowledge that separates the researchers who produce knowledge from the practitioners who might use it; secondly, the idea of a 'know-do' gap, which implies that knowledge and practice can be separate both analytically and empirically; thirdly, the notion that practice consists of a series of largely rational decisions. These concerns echo the views expressed by others, leading some authors to call for a change of thinking to see the knowledge-practice gap not as a translation or transfer gap, but more fundamentally as a knowledge production problem. This is the stance adopted by Van de Ven and Johnson (9) in their call for a model of engaged scholarship, whereby researchers and producers collaborate in the entire joint enterprise of knowledge production and use. Similarly, Davies et al. (10) propose the use of metaphors such as 'knowledge interaction' and 'knowledge intermediation' that more accurately reflect the complex, collaborative and contextspecific processes involved. This also reflects the debate in the management literature around relevant and useful knowledge and the view that whilst researchers may undertake relevant research, this may not be what managers want and need; a situation that Markides (11) describes as not so much a lost in translation gap', but rather a 'lost before translation' issue.

What then are the implications for the translational science agenda in healthcare? Few could argue that we need to find ways to deliver the most effective, high quality, acceptable healthcare to the populations that we serve in as safe, timely and efficient a way as possible. However, in seeking to address the persistent challenges of service improvement and the uptake and diffusion of innovations in healthcare, we need to reflect upon the basic concepts of knowledge, research and evidence. Who is leading the research agenda and who decides on the priorities for research? Do these reflect the questions and concerns of those who receive, deliver or manage healthcare, or are they the domain of the academic community who carry out much of the research? Do we value tacit, experiential knowledge as much as formal, explicit knowledge? What is the relationship between the producers and users of research? Do we still have a 'two communities' model (12), or is there a need to embrace models of co-production (13), whereby users and producers of research work together to define, design and conduct studies that address real-life questions from the practice, management or policy perspective. These are important issues that we need to consider and debate if we want to move beyond discussing the problems of evidence uptake and really advance our understanding of translational science for the benefit of patients, populations and health systems.

\section{Ethical issues}

Not applicable.

\section{Competing interests}

The author declares that she has no competing interests.

\section{Author's contribution}

$\mathrm{GH}$ is the single author of the manuscript.

\section{References}

1. Schuster M, McGlynn E, Brook RH. How good is the quality of health care in the United States? Milbank Q 1998; 76: 517-63.

2. Grol R. Successes and failures in the implementation of evidence-based guidelines for clinical practice. Med Care 2001; 39: 1146-54.

3. Walshe K, Rundall T. Evidence-based management: from theory to practice in health care. Milbank Q 2001; 79: 429-57.

4. Pfeffer J, Sutton RI. Hard Facts, Dangerous Half-Truths, and Total Nonsense: Profiting from Evidence-Based Management. Harvard: Harvard Business School Press; 2006.

5. Dopson S, Fitzgerald L. Knowledge to Action? Evidence-based health care in context. Oxford: Oxford University Press; 2005.

6. Rycroft-Malone J, Seers K, Titchen A, Harvey G, Kitson A, McCormack B. What counts as evidence in evidence-based practice? J Adv Nurs 2004; 47: 81-90.

7. Greenhalgh T, Wieringa S. Is it time to drop the 'knowledge translation' metaphor? A critical literature review. J R Soc Med 2011; 104: 501-9.

8. Brown JS, Duguid P. Knowledge and organization: A social-practice perspective. Organization Science 2001; 12: 198-213.

9. Van de Ven AH, Johnson PE. Knowledge for theory and practice. Acad Manage Rev 2006; 31: 802-21.

10. Davies HTO, Nutley SM, Walter I. Why 'knowledge transfer' is misconceived for applied social research. J Health Serv Res Policy 2008; 13: 188-90.

11. Markides C. Crossing the Chasm: How to convert relevant research into managerially useful research. J Appl Behav Sci 2011; 47: 121-34.

12. Nutley SM, Walter I, Davies HTO. Using Evidence: How research can inform public services. Bristol: The Policy Press; 2007.

13. Powell K, Kitson A, Hoon E, Newbury J, Wilson A, Beilby J. A study protocol for applying the co-creating knowledge translation framework to a population health study. Implement Sci 2013; 8: 98. 